\title{
Composition Design and Performance Evaluation of Emulsified Asphalt Cold Recycled Mixtures
}

\author{
Yuhui $\mathrm{Pi}^{1}$, Zhe Huang ${ }^{2, *}$, Yingxing $\mathrm{Pi}^{1}$, Guangcan $\mathrm{Li}^{2}$ and $\mathrm{Yan}^{\mathrm{Li}}{ }^{2}{ }^{\mathbb{C}}$ \\ 1 School of Civil Engineering and Architecture, Chongqing Vocational Institute of Engineering, \\ Chongqing 402260, China \\ 2 School of Highway, Chang'an University, Xi'an 710064, China \\ * Correspondence: hz0720@chd.edu.cn; Tel.: +86-15369717558
}

Received: 20 June 2019; Accepted: 20 August 2019; Published: 22 August 2019 updates

\begin{abstract}
Based on an analysis of the cold regeneration mechanism of emulsified asphalt, the emulsified asphalt binders and cement were applied to prepare the cold recycled mixtures, and the main technical performances of the designed mixtures were evaluated, including high-temperature stability, water stability, and fatigue characteristics. A high content of $65 \%$ recycled asphalt pavement (RAP) material was used with some new aggregates and mineral powders, and the optimal emulsified asphalt binder and cement dosages were determined as $2.9 \%$ and $1.5 \%$ respectively. The technical performance test results show that: (1) The well-designed emulsified asphalt cold recycled mixtures have good high-temperature stability and water stability, and can meet the requirements of the road base layer and the lower layer. (2) When the stress level is lower, the fatigue performance of mixtures with lower emulsified asphalt binder dosage and lower cement content is better, but when the stress level is higher, the high dosage of emulsified asphalt binder is more favorable, while the cement content has little effect on the fatigue property. (3) The emulsified asphalt cold recycled mixtures have relatively poor fatigue resistance, and their fatigue life is significantly lower than that of the hot mixed asphalt mixtures.
\end{abstract}

Keywords: cold recycled asphalt mixtures; emulsified asphalt; composition design; technical performance; fatigue characteristics

\section{Introduction}

Along with the burgeoning construction of transportation infrastructures, the mileage of highways is constantly increasing; many of the early built highways have served for a long time, and highway performance obviously declines, bringing about the need for continuous maintenance and renovation. In recent years, highway repair and renovation have become increasingly arduous, and more and more used pavement materials are generated during those processes, such as asphalt pavement materials, cement concrete pavement materials, and so on. If the used pavement materials are treated as waste, it is not only a waste of resources, but also a use of landfill space, as well as a cause of environmental disruption. Therefore, applying recycling technologies to reuse recycled pavement materials will be a very effective measure, especially for recycled asphalt pavement (RAP) materials [1-4]. Among recycling technologies, cold recycling technology is the main way for asphalt pavement regeneration, and the use of emulsified asphalt binder for cold regeneration has rapidly become popular $[5,6]$. The application of emulsified asphalt cold recycled mixtures (EACRM) to pave the surface and base layers of roads can reduce construction costs, energy consumption, and environmental pollution [7]. To build a resource-saving and environment-friendly society, cold recycling technology can make full use of existing pavement materials and improve some performance defects of semi-rigid base layers, which will surely receive more and more attention. 
Due to the low strength and poor road performance, it is required to improve the material composition of EACRM so as to guarantee the durability of the pavements. The mechanism of EACRM is analyzed from a macro aspect, and the relevant factors affecting the technical performance are pointed out in [8-11]. The technical performance of EACRM designed with different RAP contents, cement contents, and gradation was evaluated according to high-temperature stability (Rutting test), low-temperature crack resistance (Low-temperature bending test), and water stability (Freeze-thaw split test and Immersion Marshall test) [12-14]. Creep and fatigue tests were used to evaluate the fatigue characteristics of EACRM by controlling the stress or strain levels, and corresponding fatigue failure characteristics and general rules were obtained [15-19]. Some scholars have analyzed the mechanism of demulsification strength of cement in EACRM from the microscopic point of view, and studied the micro-structure of mortar-aggregate interfaces and the micro-structure characteristics of simulated emulsified asphalt cement concrete [19,20].

The above studies have undoubtedly had positive influences on the improvement of the performance of EACRM, but they mainly focus on the effects of RAP content and properties, adhesion and spalling mechanism, asphalt type, additives type, and content on the pavement performance of cold recycled mixtures, and little study has been undertaken on the effects of material properties and composition ratios on the technical performance of EACRM. In addition, all the above studies used the heavy indoor compaction and Marshall methods to prepare specimens, but these molding methods cannot effectively simulate the actually filed construction, and the correlation between indoor specimens and pavement core samples is less than $70 \%$ [21]. In view of this, this study adopts the vibration compaction molding method, which is more in line with the actual situation to study the influence of material properties and composition ratio on emulsified asphalt cold recycled mixtures. The research results are of referential value in engineering practice.

\section{Materials and Experiments}

\subsection{Raw Materials}

(1) Preparation of emulsified asphalt

The emulsifier is an important component of emulsified asphalt, and plays a key role in the emulsification of asphalt [22]. The relevant performance test results show that high quality asphalt will give better technical performance, and that aggregate gradation, aggregate temperature, additional water content, cement content, and sand content significantly affect the mixing time and demulsification time [23-27]. Since the emulsified asphalt of cold recycled material needs sufficient working time after being mixed with stone, and considering the alkaline environment of cement hydration and the requirement of initial setting time, as well as ensuring that asphalt can participate in the formation of cement paste structure after demulsification, in this paper, a slow-cracking, slow-setting emulsifier was used. In this study, E-type emulsifier and No. 70 matrix asphalt were used to prepare emulsified asphalt. The main chemical components of the selected emulsifiers included the tallow alkyl diamine ethoxylate, nonylphenol ethoxylate, amino lignin, 2-propanol, and oil diamine ethoxylate. The technical specifications of 70 \# matrix asphalt all met the performance requirements. The emulsification process adopted in this paper was as follows: The first step was the preparation of the bitumen to ensure that its temperature in the emulsification equipment was controlled at around $130{ }^{\circ} \mathrm{C}$. The second step was the preparation of the soap liquid, selecting the appropriate emulsifier type and dosage, and the type and dosage of the additive to prepare an aqueous emulsifier solution (soap liquid). The last step was to add bitumen and soap liquid into the emulsifier; then, through the mechanical action of pressurization, shearing and grinding, the bitumen could form uniform and fine particles, which could be dispersed stably and evenly in the soap liquid to form an oil-in-water asphalt emulsion. The test indexes of emulsified asphalt are shown in Table 1. 
Table 1. Technical properties of emulsified asphalt.

\begin{tabular}{cccc}
\hline Indexes & Test Results & Technical Requirements & Technical Method \\
\hline $\begin{array}{c}\text { Screen residual } \\
(1.18 \mathrm{~mm}), \%\end{array}$ & $<0.1$ & $\leq 0.1$ & T0652 \\
Determination of Residue by & & & \\
Evaporation, \% & 58.7 & $\geq 55$ & T0651 \\
Demulsification Rate & Slow & Slow & T0658 \\
Charge & Cationic & Cationic & T0653 \\
Penetration $\left(25^{\circ} \mathrm{C}\right), 1 / 10 \mathrm{~mm}$ & 88 & $45-150$ & $\mathrm{~T} 0604$ \\
Softening Point, ${ }^{\circ} \mathrm{C}$ & & - & T0606 \\
Ductility $\left(15^{\circ} \mathrm{C}\right), \mathrm{cm}$ & 87.0 & $\geq 40$ & $\mathrm{~T} 0605$ \\
Storage Stability $5 \mathrm{~d}$ & 3.5 & $<5$ & $\mathrm{~T} 0655$ \\
Solubility (Trichloroethylene), \% & 99 & $>97.5$ & T0607 \\
Standard Viscosity C25.3, s & 15.0 & $10-60$ & T0621 \\
binding area & $\geq 4 / 5$ & $\geq 4 / 5$ & \\
\hline
\end{tabular}

\section{(2) Cement}

Considering the performance requirements of the pavement base, ordinary Portland cement (P.O. 32.5) was used. The test results of the cement are shown in Table 2.

Table 2. Technical properties of P.O. 32.5 cement.

\begin{tabular}{|c|c|c|c|}
\hline \multicolumn{2}{|l|}{ Indexes } & Test Result & Technical Requirements \\
\hline \multicolumn{2}{|c|}{$\begin{array}{c}\text { Fineness (\%) }(0.08 \mathrm{~mm} \text { square hole sieve } \\
\text { residue })\end{array}$} & 3.4 & $\leq 15$ \\
\hline \multicolumn{2}{|c|}{ Initial setting time (min) } & 180 & $\geq 45$ \\
\hline \multicolumn{2}{|c|}{ Final setting time (min) } & 360 & $\leq 390$ \\
\hline \multicolumn{2}{|c|}{ Stability (boiling) } & Qualified & Qualified required \\
\hline \multirow{2}{*}{ Compressive strength (MPa) } & 3 days & 20.1 & $\geq 16$ \\
\hline & 28 days & 48.8 & $\geq 42.5$ \\
\hline \multirow{2}{*}{ Flexural strength (MPa) } & 3 days & 4.6 & $\geq 3.4$ \\
\hline & 28 days & 7.8 & $\geq 6.4$ \\
\hline
\end{tabular}

(3) Mixture gradation

Yang et al studied the effects of RAP materials on the performances of cement stabilized recycled mixture, and indicated that optimal aggregates gradation should be designed before the determination of optimal contents of emulsified asphalt binder and cement [28]. So, in this study, the vibration compaction method was applied to determine the aggregate gradation as $65 \%$ RAP materials, $13 \%$ new aggregates $(0-3 \mathrm{~mm}), 20 \%$ new aggregates $(10-20 \mathrm{~mm})$, and $2 \%$ mineral powders. The actual gradation results are shown in Table 3, which met the requirements of the gradation range of medium size in "Technical Specification for Asphalt Pavement Regeneration of Highway" JTG F41-2008. The gradation curve of cold recycled emulsified asphalt mixtures is shown in Figure 1.

Table 3. Passing rate of the key sieve for the design mixture.

\begin{tabular}{cccccccc}
\hline Sieve size $/ \mathrm{mm}$ & 26.5 & 19 & 9.5 & 4.75 & 2.36 & 0.3 & 0.075 \\
\hline Passing rate/\% & 100 & 99.4 & 67.0 & 44.3 & 29.2 & 9.1 & 4.9 \\
\hline
\end{tabular}




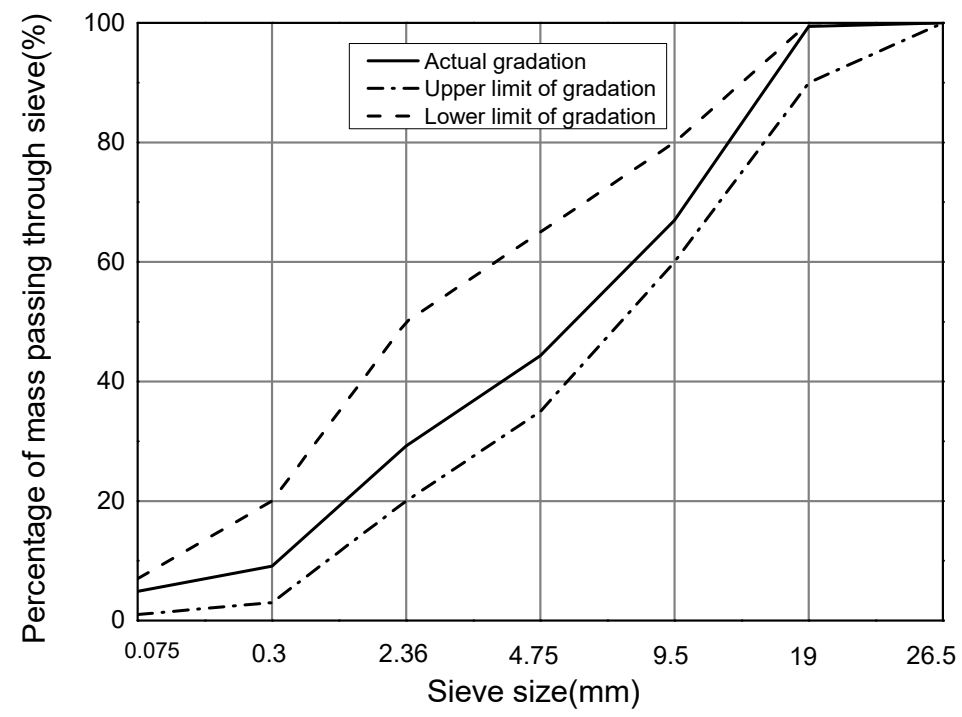

Figure 1. Gradation Curve of Emulsified Asphalt Cold Recycling Mixtures (65\%RAP).

\subsection{Design of Emulsified Asphalt Cold Recycled Mixtures}

The interaction between asphalt and filler plays a key role in the performance of asphalt mixtures, and is influenced by material properties [29,30]. The amount of cement used in this study was $1.0 \%$, $1.5 \%$, and $2.0 \%$ of the total mass of RAP and new aggregates. The amount of emulsified asphalt was set as $2.2 \%, 2.9 \%, 3.6 \%$, and $4.3 \%$ of the mass of total aggregate [31,32]. The vibratory compaction method was used to design the mix ratio, and the optimum mix ratio was determined by the Marshall method. The Marshall stability variation with the emulsified asphalt dosage are shown in Figure 2. Variations of the void volume with different asphalt content are shown in Figure 3.

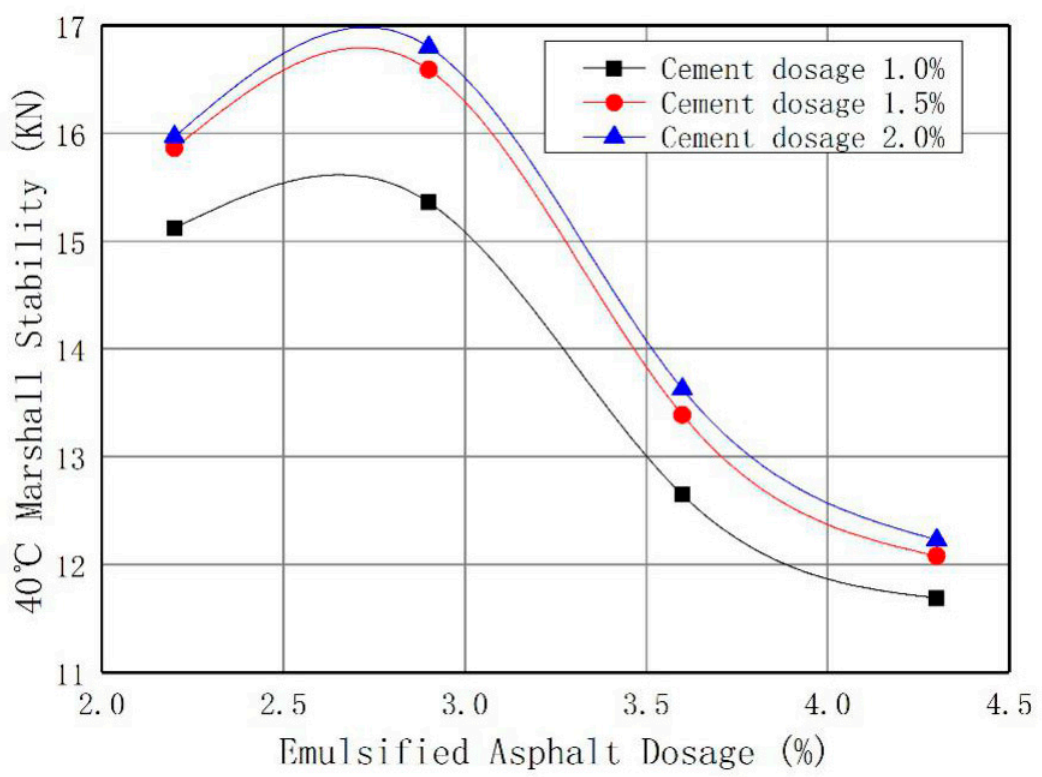

Figure 2. Marshall Stability Trend Chart. 


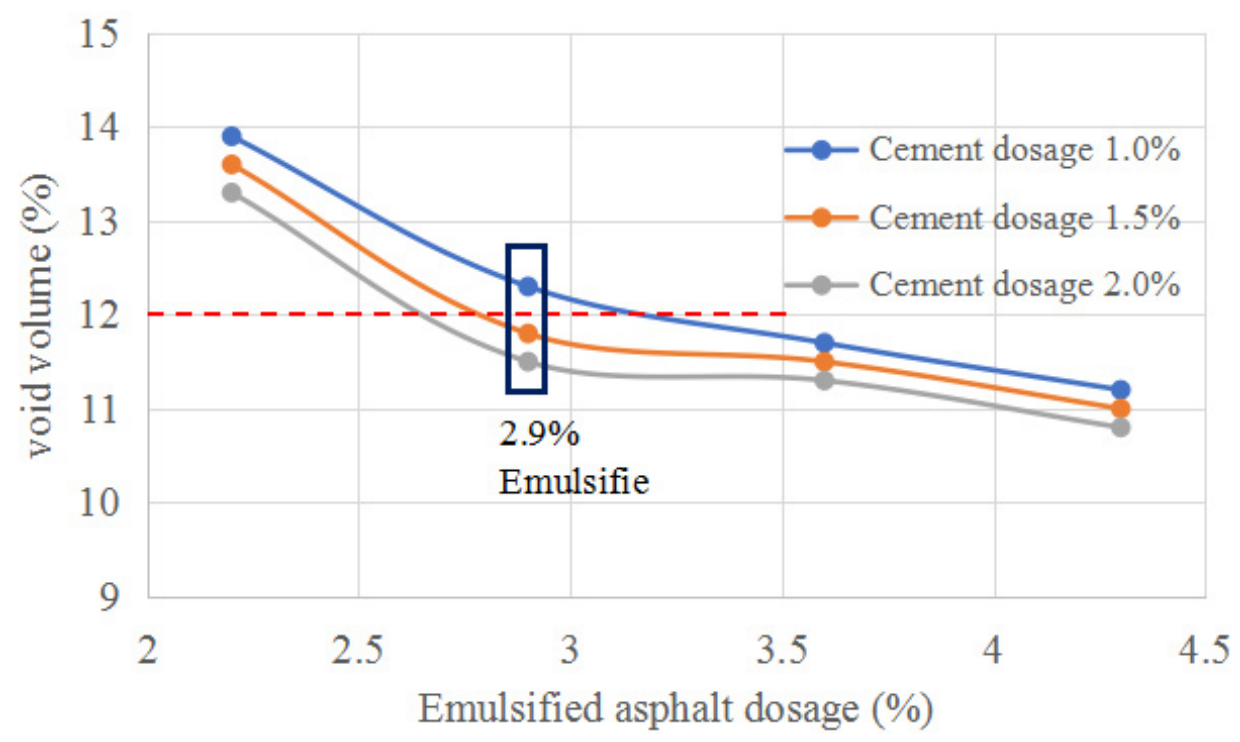

Figure 3. Void volume Trend Chart.

The test results showed that the void volume of three kinds of specimens with different cement contents decreased with an increase of emulsified asphalt. China's current specification, "Technical Specification for Highway Asphalt Pavement Regeneration" (JTG F41-2008), requires that the void ratio of emulsified asphalt cold recycled mixtures be $9-14 \%$; the recommended void ratio is less than $12 \%$. When the content of emulsified asphalt is $2.5-2.9 \%$, Marshall stability is the best, so $2.9 \%$ emulsified asphalt content is optimal. In this case, $2.9 \%$ emulsified asphalt and $1.5 \%$ or $2.0 \%$ cement cold recycled mixtures meet the technical requirements. In addition, adding a certain amount of cement can improve the performance of cold recycled mixtures, but excessive cement will lead to the deterioration of water stability and shrinkage characteristics of mixtures. Therefore, it is suggested that the cement content should be less than 1.5\% in China's specifications, so emulsified asphalt $2.9 \%$ and cement $1.5 \%$ are optimal. The splitting test results of cold recycled emulsified asphalt mixtures are shown in Table 4 .

Table 4. Splitting test results of emulsified asphalt cold recycled mixtures.

\begin{tabular}{cccc}
\hline Cement Content (\%) & $\begin{array}{c}\text { Emulsified Asphalt } \\
\text { Content (\%) }\end{array}$ & $\begin{array}{c}\mathbf{1 5}{ }^{\circ} \mathbf{C} \text { Splitting } \\
\text { Strength (MPa) }\end{array}$ & $\begin{array}{c}\text { Technical } \\
\text { Requirements (MPa) }\end{array}$ \\
\hline 1.0 & 2.9 & 0.56 & $\geq 0.5$ \\
1.5 & 2.9 & 0.59 & \\
2.0 & 2.9 & 0.61 & \\
\hline
\end{tabular}

Gross volume density can reflect the compaction degree of the mixture specimen, and the degree of compaction affects water stability, strength, etc., to a certain extent [33]. Therefore, it was necessary to measure the gross volume density as a reference for the performance of the mixture. The gross volume density test was carried out with the cement content of RAP and aggregate of $1.5 \%$, and emulsified asphalt content of $2.9 \%$. The measured value of gross volume density was $2.210 \mathrm{~g} / \mathrm{cm}^{3}$.

The maximum theoretical density is the density reflecting aggregate gradation theory under certain conditions. Under certain conditions, it can reflect the density of the mixture itself, and can reflect the density of gradation. Maximum theoretical density can reflect the quality of gradation. Combined with gross volume density of the specimen, the void volume can be calculated. The theoretical maximum density was $2.51 \mathrm{~g} / \mathrm{cm}^{3}$.

The void volume was $11.9 \%$. It can be seen that the void volume meets the requirement of the specification, but it was too large, and so poorly resistant to water damage, which required the asphalt to have good bonding performance. 


\subsection{Specimens Preparation and Experimental Methods}

The first step was to change the amount of cement and emulsified asphalt in the mixture, use the vibration molding method to design the mixture ratio, and decide the best mix ratio by Marshall test. The next step was to study the technical performance, including the volume characteristics of the mixture, water stability, and high-temperature stability of the Marshall test specimens made from the above type of asphalt mixture. The third step was to carry out fatigue tests of $2-4 \%$ cement content and 3-5\% asphalt content test pieces under different stress conditions, analyze the factors affecting the fatigue performance of cold recycled mixtures, and compare the fatigue lives with those of other materials.

In this study, the vibration compaction method was used to form the specimens; the main working parameters of the vibratory compaction molding machine are as follows: the vibration frequency is $30 \mathrm{~Hz}$, the amplitude is $0-25 \mathrm{~mm}$, the static pressure is $2500 \mathrm{~N}$, the exciting force is $9000 \mathrm{~N}$, and the compaction function is adjusted by changing the vibratory compaction time. The gross volume density of the specimens was measured when they were compacted 50 times, cured at 60 for $40 \mathrm{~h}$, compacted 25 times and cooled at room temperature for $12 \mathrm{~h}$, and was measured using the underwater weighing method T0706-2000. The high-temperature stability was evaluated by a rutting test. The size of specimens used in the rutting test is $300 \mathrm{~mm} \times 300 \mathrm{~mm} \times 80 \mathrm{~mm}$; the rutting test was conducted according to "asphalt mixture rutting test" (T0719-2011). The temperature of the test is controlled at $(60 \pm 0.5){ }^{\circ} \mathrm{C}$ and the tire pressure is $(0.7 \pm 0.05) \mathrm{MPa}$. The water stability of the specimens was evaluated by splitting strength test. The steps are as follows: after forming the specimens under the same conditions, the strength of the specimens are measured after natural curing for seven days. The fatigue properties of recycled mixtures are evaluated by indirect tensile fatigue test. According to the research results of SHRP, the fatigue failure above room temperature is mainly caused by the accumulation of deformation of materials, which has no significant fatigue significance. Therefore, SHRP suggests that fatigue failure above $20{ }^{\circ} \mathrm{C}$ should not be considered. The criterion of fatigue life is as follows: with an increase of loading times, the vertical deformation of specimens develops from stable stage to accelerated growth stage, and the number of loading times corresponding to the inflection point is defined as the number of fatigue failure effect [34]. Steps are given as follows: (1) Naturally cure the mixtures for three months after specimens have been formed whose size is $\varphi 150$ $\times 150$; and (2) Conduct a fatigue test on UTM-16 material testing machine at $15^{\circ} \mathrm{C}$ by applying the sine-wave load with the frequency of $10 \mathrm{~Hz}$. Five replicates for each condition were used.

\section{Performance Evaluation of Emulsified Asphalt Cold Recycled Mixtures}

\subsection{High-Temperature Stability}

High-temperature stability is one of the main indexes by which to evaluate the durability of asphalt mixtures. The heterogeneity of the asphalt mixture was determined by studying the movement characteristics of aggregate particles in asphalt mixture under load and temperature [35]. Rutting tests were conducted to reflect the resistance of cement cement-emulsified asphalt cold recycled mixtures to resist deformation at high-temperature.

For asphalt materials, the high-temperature stability of the materials used for road surface was the main consideration, while the temperature changes of the base layer and were relatively slow. At the same time, the emulsified asphalt content of the base layer was small, and the strength formation was mainly based on the strength of cement. The dynamic stability of the two gradations is shown in Table 5 . 
Table 5. Dynamic stability of two gradations.

\begin{tabular}{cccc}
\hline Grading Type & $\begin{array}{c}\mathbf{4 5} \mathbf{m i n} \\
\text { Deformation/mm }\end{array}$ & $\begin{array}{c}\mathbf{6 0} \mathbf{m i n} \\
\text { Deformation/mm }\end{array}$ & $\begin{array}{c}\text { Dynamic } \\
\text { Stability/Cycles } \cdot \mathbf{m m}^{-\mathbf{1}}\end{array}$ \\
\hline $100 \%$ RAP & 3.683 & 4.087 & 1560 \\
$65 \%$ RAP & 3.293 & 3.535 & 2157 \\
\hline
\end{tabular}

It can be seen that the dynamic stability of cold recycled mixture with 65\% RAP is much higher than with $100 \%$ RAP, because of the incorporation of cement and the addition of emulsified asphalt. In addition, the technical requirement for dynamic stability of normal asphalt mixture is $800 \mathrm{cycles} / \mathrm{mm}$ according to the Chinese specification, and the dynamic stability of cement-emulsified asphalt mixture with $100 \%$ RAP can reach twice of the requirement. This means that the cement-emulsified asphalt mixture with $100 \%$ RAP could be applied as the asphalt layers in the pavements.

\subsection{Water Stability}

Water damage is one of the main problems of asphalt pavements. In general, the freeze-thaw splitting test in cold regions of the north can reflect water stability. For the rainy and warm climates in the southern areas, there is no freeze-thaw cycle, and the wet-dry splitting strength can be used as the control index of water stability. Studies have also found that [36,37] during the curing period, proper rainwater is beneficial for the strength of the mixture, because the hydration of cement cannot be separated from water. Proper rainwater contact is ensured in the early stage the curing period, and the actual road curing effect is better. Therefore, in this study, the strength of Marshall specimens was measured by natural curing for seven days under the same conditions. The freeze-thaw splitting strength and the wet-dry splitting strength are shown in Figure 4. Dry, freeze-thaw and wet splitting strengths of cold recycled emulsified asphalt mixtures are shown in Table 6.

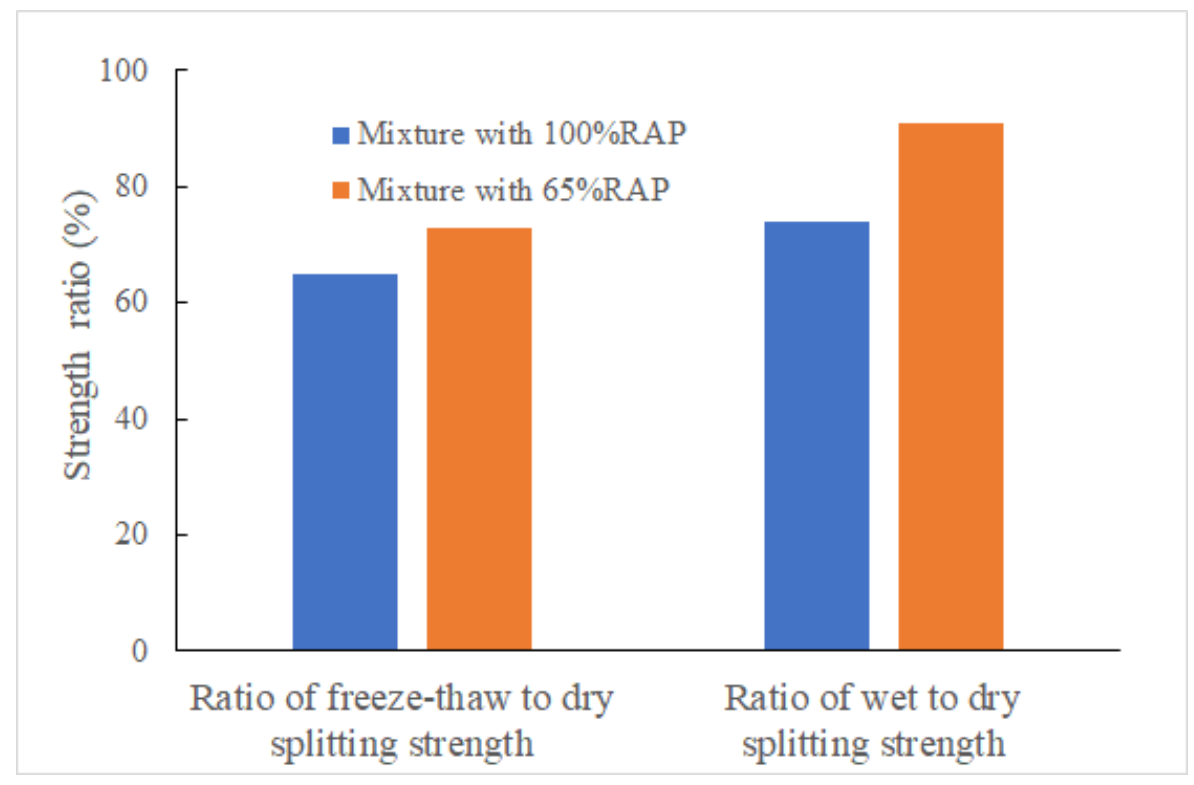

Figure 4. Comparison of Strength of Two Mixtures.

Table 6. The dry, freeze-thaw and wet splitting strengths.

\begin{tabular}{cccc}
\hline Mixtures Type & $\begin{array}{c}\text { Dry Splitting } \\
\text { Strength (MPa) }\end{array}$ & $\begin{array}{c}\text { Freeze-Thaw Splitting } \\
\text { Strength (MPa) }\end{array}$ & $\begin{array}{c}\text { Wet Splitting Strength } \\
\text { (MPa) }\end{array}$ \\
\hline Mixture with 100\%RAP & 0.23 & 0.15 & 0.17 \\
Mixture with 65\%RAP & 0.45 & 0.33 & 0.41 \\
\hline
\end{tabular}




\subsection{Fatigue Property}

Emulsified asphalt cold recycled mixtures are generally used for pavement bases, and fatigue damage is one of the main failure modes of pavement base structures. Therefore, fatigue properties are an important evaluation indicator of base materials [38]. In this study, fatigue tests of $2-4 \%$ cement content and 3-5\% asphalt content test under different stresses conditions were carried out. The test results are shown in Table 7.

Table 7. Fatigue times of recycled materials with different parameters.

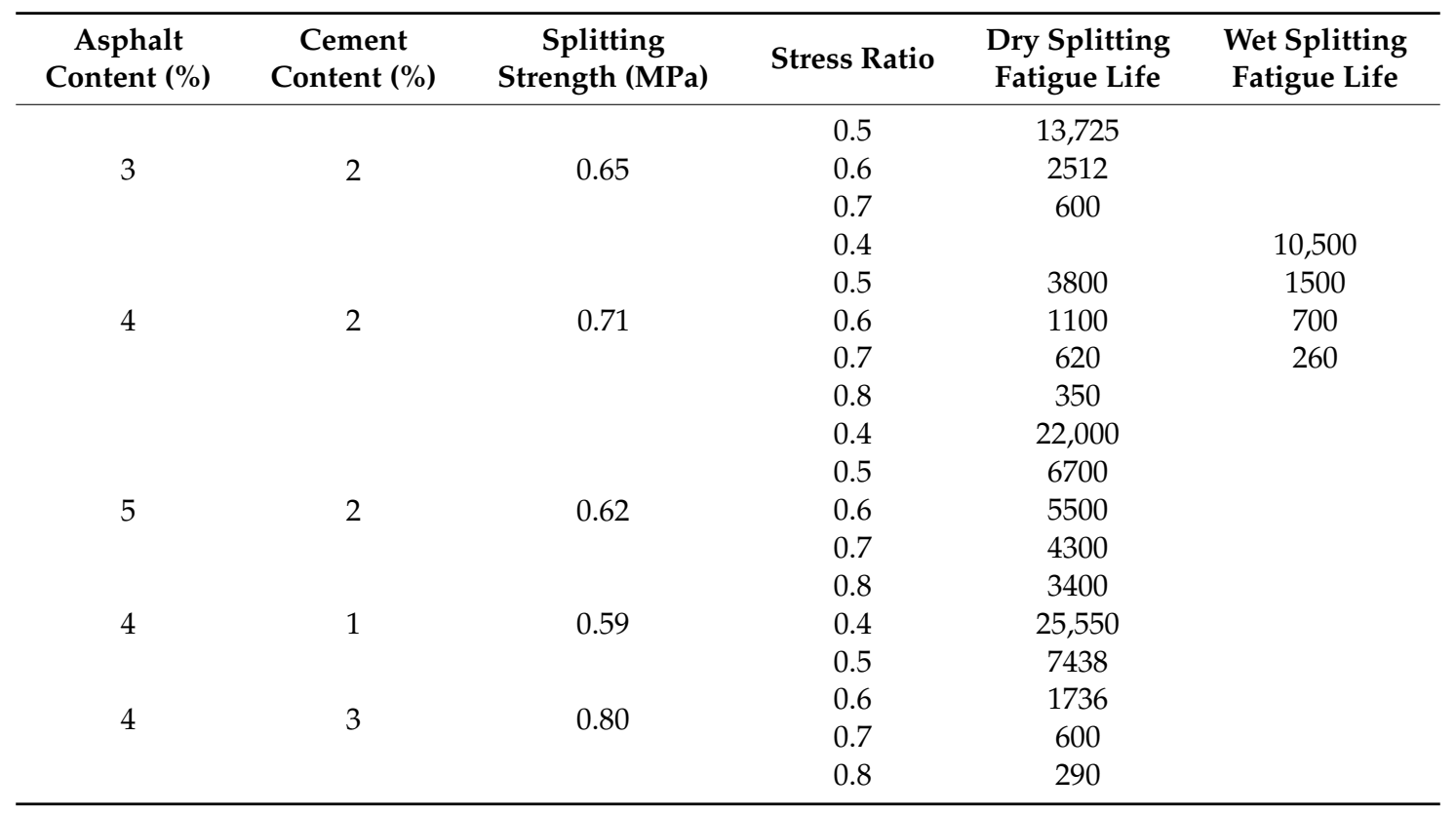

According to the results of previous studies, the relationship between fatigue number and stress ratio can be better reflected by fitting fatigue equations into a logarithmic form. Therefore, the relationship between the fatigue times and the stress is:

$$
\frac{\sigma}{\sigma_{f}}=a N^{c}
$$

where $\sigma$ is the ultimate tensile strength of the recycled mixtures; $\sigma_{f}$ is Allowable tensile stress; and $N$ is the -Fatigue life; $a$ and $c$-are the regression coefficients.

This formula, taken the logarithm on both sides, can get $\log \left(\frac{\sigma}{\sigma_{f}}\right)=\log \left(a N^{c}\right)$, i.e., $\log \left(\frac{\sigma}{\sigma_{f}}\right)=\log a+c \log N$; that is to say, it can linearly regress into a linear equation $y=c * x+m$, such as $y=\log \left(\frac{\sigma}{\sigma_{f}}\right), m=\log a, x=\log N$.

It can be seen from the fitting relationship in Figure 5 that the logarithm of the fatigue times of the wet and dry splitting fatigue and the logarithm of stress ratio satisfy the linear relationship. This can indicate that the number of fatigue times and the stress ratio fitted by this function are of practical value. The fatigue equations for different dosages are shown in Table 8. 


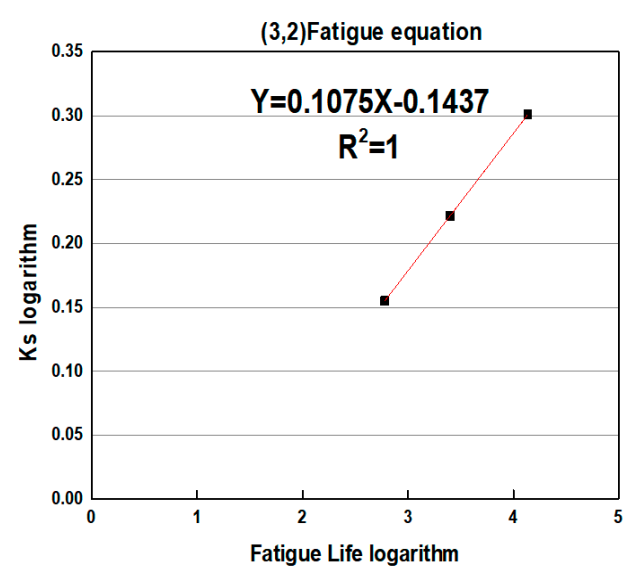

(a)

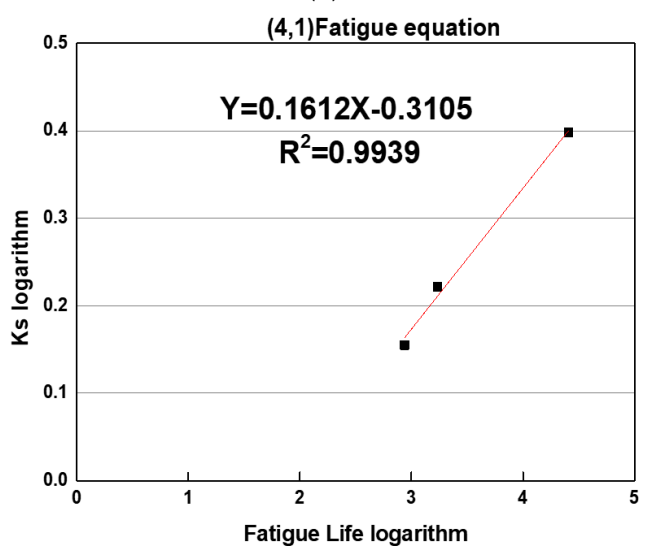

(c)

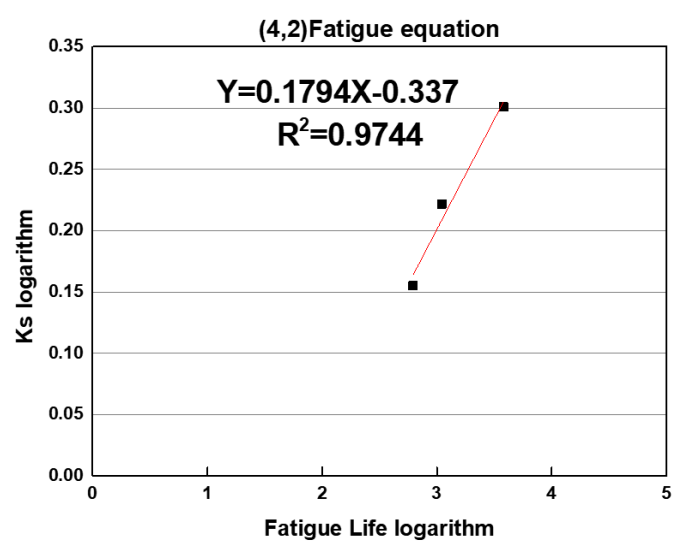

(b)

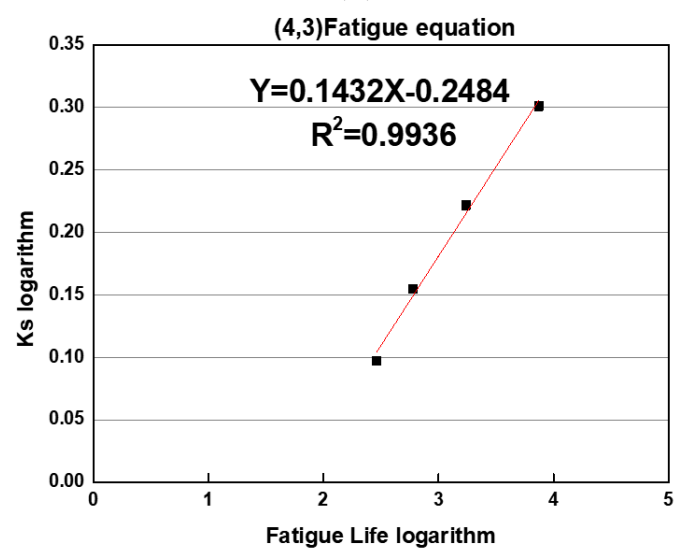

(d)

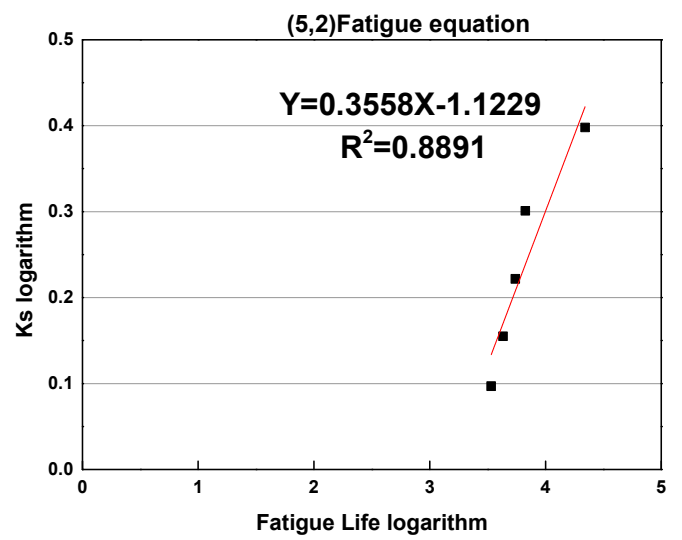

(e)

Figure 5. Logarithm of fatigue life with different parameters. (a) $(3,2)$ Fatigue equation; $(\mathbf{b})(4,2)$ fatigue equation; (c) $(4,1)$ fatigue equation; (d) $(4,3)$ fatigue equation; (e) $(5,2)$ fatigue equation.

Table 8. Fatigue equations for different asphalt and cement contents.

\begin{tabular}{ccc}
\hline Emulsified Asphalt and Cement Content & Linear Equation & Fatigue Equation \\
\hline$(3 \%, 2 \%)$ & $\mathrm{y}=0.1075 \mathrm{x}-0.1437$ & $\log \frac{\sigma}{\sigma_{f}}=0.1075 \log N-0.1437$ \\
$(4 \%, 2 \%)$ & $\mathrm{y}=0.1794 \mathrm{x}-0.337$ & $\log \frac{\sigma}{\sigma_{f}}=0.1794 \log N-0.337$ \\
$(5 \%, 2 \%)$ & $\mathrm{y}=0.3558 \mathrm{x}-1.1229$ & $\log \frac{\sigma}{\sigma_{f}}=0.3558 \log N-1.1229$ \\
$(4 \%, 1 \%)$ & $\mathrm{y}=0.1612 \mathrm{x}-0.3105$ & $\log \frac{\sigma}{\sigma_{f}}=0.1612 \log N-0.3105$ \\
$(4 \%, 3 \%)$ & $\mathrm{y}=0.1432 \mathrm{x}-0.2484$ & $\log \frac{\sigma}{\sigma_{f}}=0.1432 \log N-0.2484$ \\
\hline
\end{tabular}




\section{Influencing Factors of Fatigue Properties for Emulsified Asphalt Cold Recycled Mixtures}

\subsection{Effect of Humidity on Fatigue Life of Specimens}

This study selected a group with $4 \%$ asphalt content and $2 \%$ cement content and compared their wet-dry splitting fatigues. The result is shown in Figure 6.

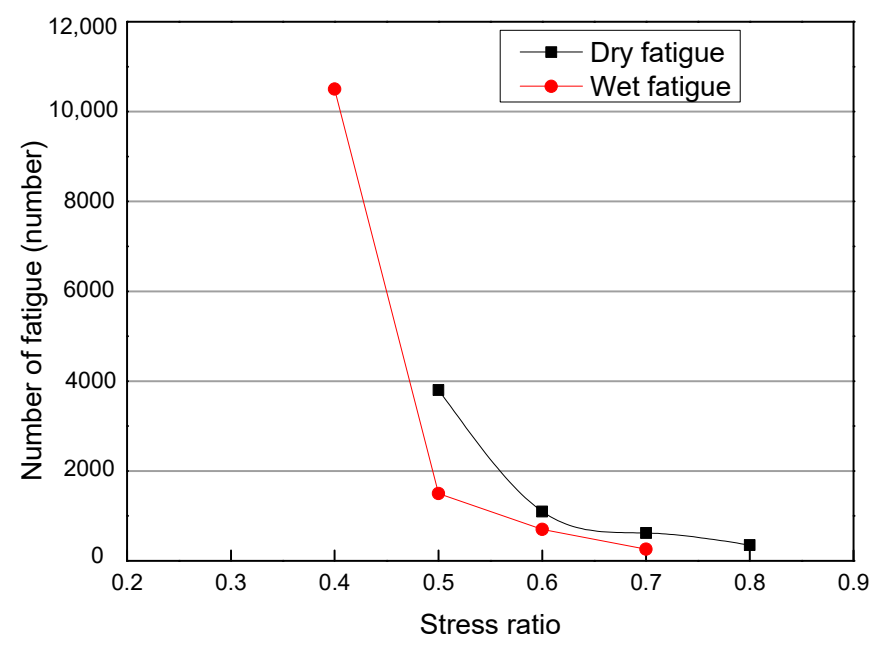

Figure 6. Comparison of dry and wet fatigue times.

From Figure 6, it can be seen that the number of dry fatigue times is more than that of wet fatigue times corresponding to the same stress, and the greater the stress ratio, the less obvious the difference of fatigue times. That is to say, for the cold recycled structural layer, the application of repeated loads under wet conditions should be avoided.

\subsection{Effect of the Amount of Emulsified Asphalt on the Fatigue Life of Specimens}

Figure 7 shows the fatigue times of three kinds of emulsified asphalts with $3 \%, 4 \%$, and $5 \%$ asphalt contents and under different stress ratios with the same cement contents; the results show that the influence of emulsified asphalt content on the fatigue properties of specimens is complex. At low stress ratios, low emulsified asphalt dosages appear to be advantageous; but at high stress ratios, high emulsified asphalt dosages appear to be advantageous. In addition to the test errors, the main reason for the above test results is that the controlled stress fatigue mode was adopted in this test. This test method is not suitable for flexible materials, so it is insensitive to the reaction of asphalt dosage.

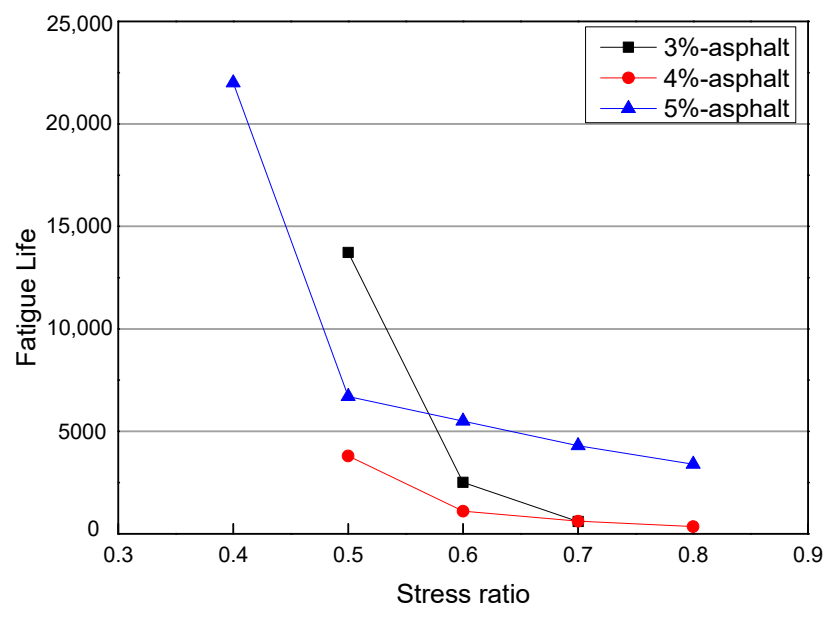

Figure 7. Fatigue times of different asphalt contents. 


\subsection{Effect of the Amount of Cement on the Fatigue Life of Specimens}

Three emulsified asphalts with an asphalt content of $4 \%$ and cement contents of $1 \%, 2 \%$, and $3 \%$ were selected for fatigue tests under different stress ratios. From the fatigue times under the corresponding stress ratio, it can be found that under a low stress ratio, the fatigue performance is better under the low cement content; while at the high stress ratios, the cement content has little effect on the fatigue times. The fatigue time of different cement content is shown in Figure 8.

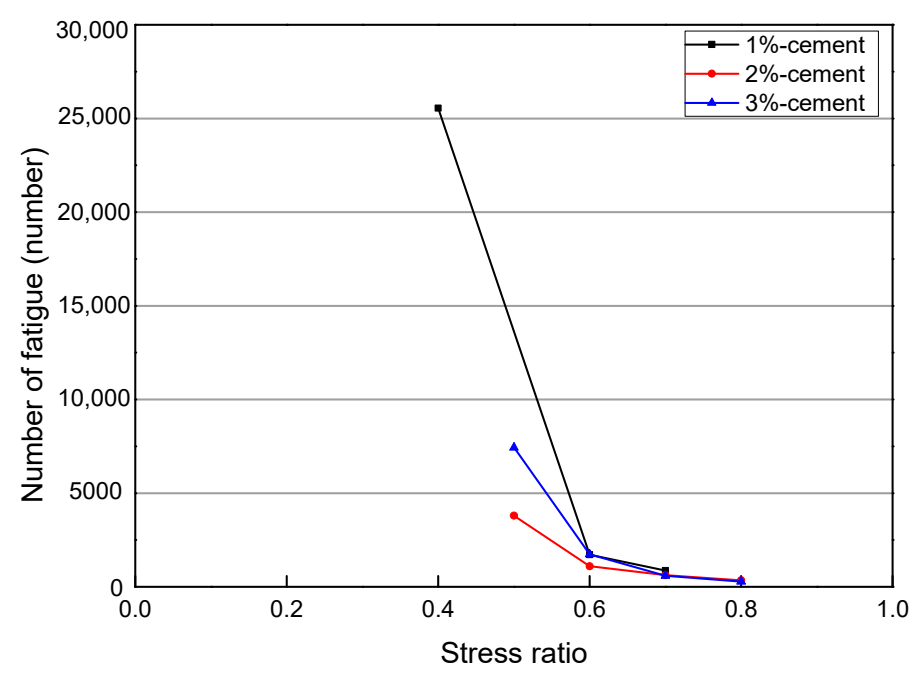

Figure 8. Fatigue times of different cement contents.

\subsection{Comparison with Other Materials}

Because of the great difference between the indoor fatigue test and the actual fatigue process of pavements, it is difficult to evaluate the anti-fatigue performance simply by looking at the indoor fatigue test results. For this reason, this paper conducted a comparative study on emulsified asphalt cold recycled mixtures, foamed asphalt cold recycled mixtures, and hot asphalt mixtures.

For foamed asphalt cold recycled mixtures, the same RAP materials and aggregate gradation as emulsified asphalt cold recycled mixtures were used. The asphalt was firstly foamed at $150{ }^{\circ} \mathrm{C}$ with $2.0 \%$ water consumption, the optimum foamed asphalt contents was determined as $2.0 \%$, and the water content added in mixing process was determined as $4.8 \%$. The aggregate gradation for hot asphalt mixtures is the same as that of temulsified asphalt cold recycled mixtures, and the optimal asphalt content is determined as $5.3 \%$.

The fatigue life of cold recycled emulsified asphalt mixtures was compared with that of hot mix asphalt mixtures, and the relationship between stress ratio and fatigue times is shown in Figure 9 [39,40].

From Figure 9, it can be seen that the performance of emulsified asphalt cold recycled mixtures is not as good as that of the hot mix asphalt mixtures, in terms of fatigue times and high-low stress ratios. The strength of the hot mix asphalt mixtures is higher than that of the recycled material. Therefore, under the same stress ratio, hot mix asphalt mixtures tend to bear much more stress than the recycled material test specimens. Under the same stress level, the fatigue life of the hot mix asphalt mixtures is higher than that of the recycled materials, and the sensitivity of recycled material to stress increase is greater than that of hot mix asphalt.

Foamed bitumen is another way of cold recycling. In the process of cold recycling, the addition of active materials, such as cement, is also a major aspect of strength enhancement. According to the fatigue data of foam cold recycled asphalt, this study drew a curve and compared its fatigue characteristics with those of cement emulsified asphalt. The fatigue life of the cement emulsified asphalt cold recycled material was compared with the fatigue life of foam cold recycled asphalt mixtures. The relationship between the stress ratio and the fatigue number is shown in Figure 10. 


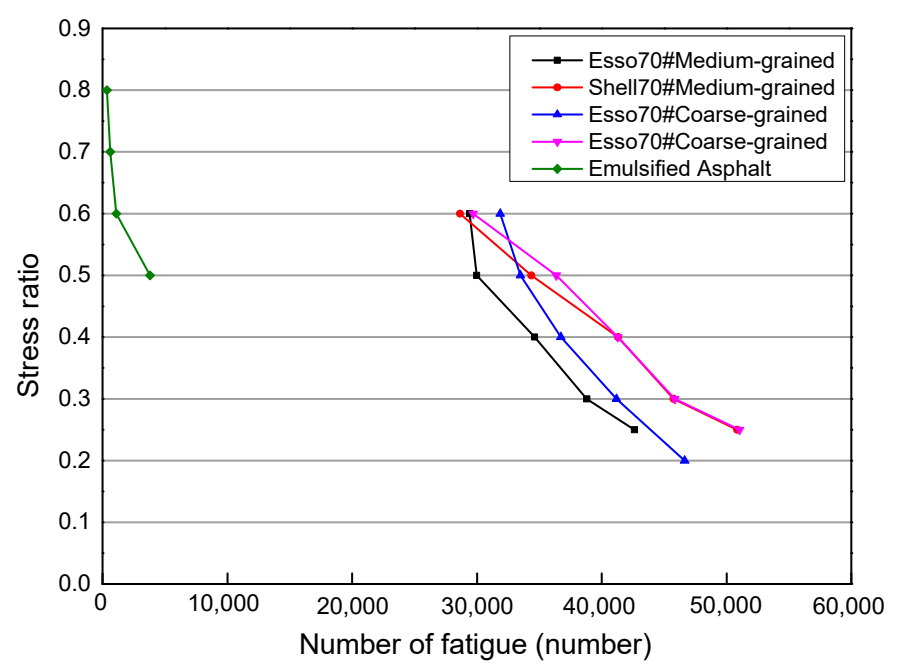

Figure 9. Comparison of Emulsified Asphalt Cold Recycled Mixtures and Hot Mix Asphalt Mixtures.

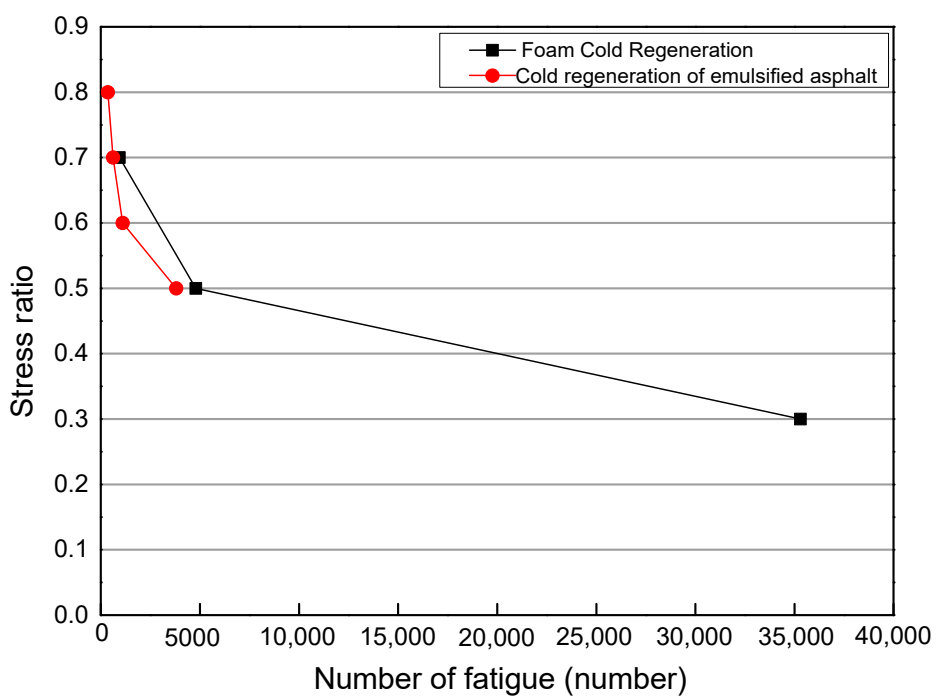

Figure 10. Comparison of emulsified asphalt cold recycled mixtures and foamed asphalt mixtures.

It can be seen from Figure 10 that compared with the emulsified asphalt mixtures, the fatigue life of the foam cold recycled mixtures is almost the same as that of the emulsified asphalt mixtures. It can therefore be said that the fatigue degree of the two mixtures is equal.

\section{Summary and Conclusions}

Based on the analysis of the mechanism of cold recycled emulsified asphalt, a series of pavement performances, including composition design, high temperature stability, water stability, and fatigue characteristics of emulsified asphalt cold recycled mixtures, were studied in the laboratory by the vibration compaction molding method, which is more in line with real-world situations. The main conclusions are as follows:

(1) The composition design of emulsified asphalt cold recycled mixtures was carried out by the vibration forming method. The results show that the performance of the mixture with $65 \%$ RAP meets the requirements. The proportion of the design grading is: RAP materials: $0-3 \mathrm{~mm}$ aggregates: $10-20 \mathrm{~mm}$ aggregates: mineral powder $=65: 13: 20: 2$, the optimal emulsified asphalt binder and cement dosages were determined as $2.9 \%$ and $1.5 \%$ respectively.

(2) The developed emulsified asphalt meets the technical requirements and can be used in the composition design of cold recycled mixtures. The well-designed emulsified asphalt cold recycled 
mixtures have good high-temperature stability and water stability, which can meet the application requirements for a highway base and underlying layer.

(3) When the stress level is lower, the fatigue performance of the mixture with low emulsified asphalt dosage is better; when the stress level is higher, the dosage of high emulsified asphalt is more favorable; when the stress level is lower, the fatigue performance under low cement content is better; but when the stress level is high, the cement content has little effect on the fatigue frequency.

(4) Emulsified asphalt cold recycled mixtures have poor fatigue resistance and lower fatigue life than hot mix asphalt mixtures. Under the same stress level, the fatigue life of the hot mix asphalt mixture is higher than that of the recycled materials, and the sensitivity of recycled material to stress increase is greater than that of hot mix asphalt. Therefore, in structural design, the cold recycled structure layer should, as far as possible, not be placed in the bending-tension fatigue zone.

Author Contributions: Conceptualization, Y.P. (Yuhui Pi), Z.H. and Y.P. (Yingxing Pi); methodology, Y.P. (Yuhui Pi), Z.H., Y.P. (Yingxing Pi), G.L. and Y.L.; software, Y.P. (Yuhui Pi) and Y.P. (Yingxing Pi); validation, Y.P. (Yuhui Pi), Z.H., Y.P. (Yingxing Pi), G.L. and Y.L.; formal analysis, Y.P. (Yuhui Pi), Z.H., Y.P. (Yingxing Pi), G.L. and Y.L.; investigation, Y.P. (Yuhui Pi), Z.H., Y.P. (Yingxing Pi), G.L. and Y.L.; resources, Y.P. (Yuhui Pi), Z.H., Y.P. (Yingxing Pi), G.L. and Y.L.; data curation, Y.P. (Yuhui Pi), Z.H., Y.P. (Yingxing Pi), G.L. and Y.L.; writing-original draft preparation, Z.H.; writing - review and editing, Z.H.; visualization, Y.P. (Yuhui Pi), Z.H., Y.P. (Yingxing Pi), G.L. and Y.L.; supervision, Y.P. (Yuhui Pi), Z.H., Y.P. (Yingxing Pi), G.L. and Y.L.; project administration, Y.P. (Yuhui Pi), Z.H. and Y.P. (Yingxing Pi); funding acquisition, Y.P. (Yuhui Pi) and Y.P. (Yingxing Pi).

Funding: This work was supported by China Postdoctoral Science Foundation (No. 2017M620434), Shaanxi Postdoctoral Grant Program (No. 2017BSHYDZZ17), and the Special Fund for Basic Scientific Research of Central College of Chang'an University (No. 310821173501). The authors gratefully acknowledge their financial support.

Conflicts of Interest: The authors declare no conflict of interest.

\section{References}

1. Chen, Y.H. Analysis of Mechanical Properties of Cement Stabilized Recycled Mixture. Road Mach. Constr. Mech. 2012, 9, 65-67.

2. Zhao, G.J. Experimental study on factors affecting splitting strength of foamed asphalt recycled mixture. J. Zhengzhou Univ. Eng. Sci. 2012, 33, 72-75.

3. Wu, X.R. Comparative analysis of crack resistance of different types of asphalt mixtures. J. Water Resour. Archit. Eng. 2016, 14, 28-131.

4. Zhang, N.; Li, J.Y. Experimental study on water stability improvement of granite asphalt mixture. J. Water Resour. Archit. Eng. 2011, 9, 106-109.

5. Liu, S.H. Analysis of Cold Regeneration Mechanism of Semi-rigid Base Asphalt Concrete Pavement. Highway 2011, 5, 192-196.

6. Wang, Z.J. Improvement Mechanism of Cement on Microstructure of Emulsified Asphalt Mixture. J. Wuhan Univ. Technol. 2009, 31, 16-19.

7. Zhang, D.L. Design of mixture mixing ratio for emulsified bitumen cold regenerated surface. Urban Roads Bridges Flood Control 2010, 16, 25-28.

8. Sun, Y.S. Influence of Portland cement on the performance of emulsified asphalt cold regeneration. J. Wuhan Univ. Technol. 2013, 35, 45-48. (In Chinese)

9. Bissada, A.F. Structural response of foamed-asphalt-sand mixtures in hot environments, Asphalt Materials and Mixtures. In Proceedings of the 66th Annual Meeting of the Transportation, Board, Transportation Research Board, Washington, DC, USA, 12-15 January 1987; pp. 134-149.

10. Ebelsl, J. Characterisation of Material Properties and Behaviour of Cold Bituminous Mixtures for Road Pavements. Ph.D. Thesis, Stellenbosch University, Stellenbosch, South Africa, 2008.

11. Yao, D. Research on cold recycled mixture fatigue performance. Highw. Eng. 2014, 39, 322-326. (In Chinese)

12. Sravani, A.; Pramod, K.J.; Nagabhushana, M.N. Optimization of Recycled Asphalt Pavement in Cold Emulsified Mixtures by Mechanistic Characterization. J. Mat. Civ. Eng. 2015, 28, 04015132.

13. Wu, C.F.; Zeng, M.L.; Zhao, M.H.; Zhong, M.W. Experimental study on road performance of emulsified asphalt cold recycled mixture. Highw. Traffic Technol. 2009, 26, 27-32. 
14. Du, S.W. Effect of additives on pavement performance of cold recycled asphalt emulsion mixture. J. Build. Mater. 2013, 16, 534-538. (In Chinese)

15. Yan, J.H.; Ni, F.J.; Yang, M.K. Indirect tensile fatigue properties of asphalt emulsion cold recycled mixes. J. Build. Mater. 2011, 14, 58-61. (In Chinese)

16. Guo, Y.C.; Shen, A.Q.; Zhang, M.C.; Sun, Z.Z.; Nie, C.K. Influencing factors of road performance of composite cold recycled base mixture of asphalt pavement. J. Highw. Transp. Res. Dev. 2014, 31, 32-38. (In Chinese)

17. Wang, D.C.; Hao, P.W.; Wei, X.L. Fatigue performance and influence factor forcold recycling mixture with emulsified asphalt. J.Beijing Univ. Technol. 2016, 42, 541-546. (In Chinese)

18. Jiang, Y.J.; Han, Z.Q. Effect of graded paired emulsified asphalt cold recycled asphalt mixture on road performance. J. Dalian Univ. Technol. 2018, 58, 607-614.

19. Pouliot, N.; Marchand, J.; Pigeon, M. Hydrationmechanisms microstructure and mechanical properties of mortars prepared withmixed binder cement slurry-asphalt emulsion. J. Mater. Civ. Eng. 2003, 15, 54-58. [CrossRef]

20. China Communications Publishing, JTG F40-2004. Specification for Construction Technology of Highway Asphalt Pavement; People Traffic Press: Beijing, China, 2004; ISBN 7114053282. (In Chinese)

21. Li, J.; Zhang, J.; Qian, G.; Zheng, J.; Zhang, Y. Three-Dimensional Simulation of Aggregate and Asphalt Mixture Using Parameterized Shape and Size Gradation. J. Mater. Civ. Eng. 2019, 31, 04019004. [CrossRef]

22. Jiang, Y.J.; Chen, Z.J.; Xu, X.H.; Liang, H. Evaluation on vertical vibration compaction method of ATB-30 asphalt mixture. J. Build. Mater. 2014, 17, 638-643. (In Chinese)

23. Sheng, X.; Wang, M.; Xu, T.; Chen, J. Preparation properties and modification mechanism of polyurethane modified emulsified asphalt. Constr. Build. Mater. 2018, 189, 375-383. [CrossRef]

24. Zhang, J.; Tan, H.; Pei, J.; Qu, T.; Liu, W. Evaluating crack resistance of asphalt mixture based on essential fracture energy and fracture toughness. Int. J. Geomech. 2019, 19, 06019005. [CrossRef]

25. Zhang, H.B.; Guo, T.T.; Zheng, C. Study on properties of emulsified asphalt recycled mixture. Road Constr. Mach. Constr. Mech. 2014, 31, 69-71.

26. Hou, S.; Chen, C.; Zhang, J.; Shen, H.; Gu, F. Thermal and mechanical evaluations of asphalt emulsions and mixtures for microsurfacing, Construction and Building Materials. Constr. Build. Mater. 2018, 191, 1221-1229. [CrossRef]

27. Yang, F.Y.; Chen, W.F. Experimental study on road performance of cement stabilized recycled mixture. Highw. Eng. 2011, 36, 127-133.

28. Yan, J.H.; Zhu, H.R.; Zhang, X. The theoretical analysis of the RAP aged asphalt influence on the performance of asphalt emulsion cold recycled mixes. Constr. Build. Mater. 2014, 71, 444-450. [CrossRef]

29. China Communications Publishing, JTG F41-2008. Technical Specification for Asphalt Pavement Regeneration of Highway; People Traffic Press: Beijing, China, 2008; ISBN 9787114071058. (In Chinese)

30. Zhang, J.; Li, X.; Liu, G.; Pei, J. Effects of material characteristics on asphalt and filler interaction ability. Int. J. Pavement Eng. 2019, 20, 928-937. [CrossRef]

31. Pi, Y.H. Research on Materials and Structure of Emulsified Asphalt Cold Recycling for Asphalt Pavement with Semi-rigid base; School of Transportation Southeast University Press: Dhaka, Bangladesh, 2014.

32. Dong, Z.J.; Tan, Y.Q.; Cao, L.P. Research on Indoor Design and Performance Evaluation of Cold Recycled Mixture with Emulsified Asphalt. J. Highw. Transp. Res. Dev. 2006, 23, 43-47. (In Chinese)

33. Zhang, J.; Peng, J.; Zheng, J.; Dai, L.; Yao, Y. Prediction of Resilient Modulus of Compacted Cohesive Soils in South China. Int. J. Geomech. 2011, 36, 127-133. [CrossRef]

34. He, D.P.; Jin, H. Study on Mixture Ratio Design Method of Cement Emulsified Asphalt Cold Recycled Mixture Based on Air Void. China Foreign Highw. 2016, 36, 284-288.

35. Zhang, J.; Li, X.; Ma, W.; Pei, J. Characterizing heterogeneity of asphalt mixture based on aggregate particles movements. Iran. J. Sci. Technol. Trans. Civ. Eng. 2019, 43, 81-91. [CrossRef]

36. Zeng, M.L.; Yu, Y.S.; Wu, C.F.; Huang, K.Y. The effect of cement on the performance of emulsified asphalt cold recycled asphalt mixture. Highw. Traffic Technol. 2008, 4, 59-62.

37. Peng, Y.; Sun, L.J.; Shi, Y.J.; Huang, Z.Y. Influencing Factors of Splitting Strength of Asphalt Mixture. J. Jilin Univ.: Eng. Sci. 2007, 4, 1304-1307.

38. Huang, X.M.; Zhang, J.P.; Liu, W.M. Prediction of Splitting Fatigue Life of Asphalt Mixture by Viscoelastic Theory. J. South China Univ. Technol. Nat. Sci. Edition 2008, 6, 56-61. 
39. Pi, Y.H.; Huang, X.M.; Liu, W.M. Fatigue Life Prediction of Asphalt Mixture Based on Splitting Creep. J. Wuhan Univ. Technol. Transp. Sci. Eng. 2009, 6, 1044-1047.

40. Zhang, J.; Fan, Z.; Wang, H.; Sun, W.; Pei, J.; Wang, D. Prediction of dynamic modulus of asphalt mixture using micromechanical method with radial distribution functions. Mater. Struct. 2019, 52, 1-12. [CrossRef]

(C) 2019 by the authors. Licensee MDPI, Basel, Switzerland. This article is an open access article distributed under the terms and conditions of the Creative Commons Attribution (CC BY) license (http://creativecommons.org/licenses/by/4.0/). 